\title{
Injuries in Contemporary Dance
}

\author{
Wenying Sun \\ Moray House School of Education, University of Edinburgh, Edinburgh, England \\ Email: s1882500@ed.ac.uk
}

How to cite this paper: Sun, W. Y. (2020). Injuries in Contemporary Dance. Advances in Physical Education, 10, 282-292. https://doi.org/10.4236/ape.2020.103023

Received: July 17, 2020

Accepted: August 21, 2020

Published: August 24, 2020

Copyright (c) 2020 by author(s) and Scientific Research Publishing Inc. This work is licensed under the Creative Commons Attribution International License (CC BY 4.0).

http://creativecommons.org/licenses/by/4.0/

\begin{abstract}
Different dance types may lead to different injuries. Musculoskeletal injuries in dance can be divided into chronic injuries, and acute injuries. And the causes of injuries are also different. In modern dance, the most common injuries are the ankle, knee and shin. Analysis of the causes of injuries may prevent the occurrence of injuries to a certain extent. Therefore, based on the analysis of the types of injuries in modern dance, this article also discusses in teacher teaching, how to reduce the occurrence of injuries, how students should protect themselves, and how dancers extend their careers were discussed in these three aspects.
\end{abstract}

\section{Keywords}

Dance Education, Prevention, Science, Contemporary Dance Injuries, Teaching Method

\section{Introduction}

There are some risk factors for learning dance or other special projects (gymnastics, competitive sports) (Caine \& Nassar, 2005), and they have specific requirements for the physical flexibility, agility, and coordination of the dancers. Different dance types may lead to different injuries (Echegoyen et al., 2010). It is inferred that a dancer's full knowledge of the dance has learned and practiced can effectively prevent dance injuries. Because the relationship between core stability (muscle strength, endurance, strength) and dance will significantly reduce the occurrence of sports injuries and also improve the performance of dance performance (Rickman, 2012), which requires constant practice can be obtained. However, there are many challenges, such as the teaching method of the educator and the comprehensive understanding of the body structure, if this factor is not taken into consideration, it will become the main reason for students to be injured during learning and practicing dance. 
Modern dance is one of many forms of dance, and its central injuries are knees, ankles, and shin (van Winden et al., 2019). The technical skill of modern dance is different from other dance types (Weiss et al., 2008). It pays attention to the relationship between movements or the relationship between movements and space and completes painful movements by controlling itself, such as Cunningham Modern Dance System (Copeland, 2004). Therefore, the dancers have high-quality requirements. During the training process, factors such as reduced physical fitness, incomplete mastery of mechanical movements, incorrect movements, and irregular movements may cause sports injuries. Moreover, sports injuries may have multiple effects on dancers, for example, delays in training due to dance injuries, significantly reduce the level of physical function or even consume established muscle strength.

This assignment is divided into three parts, which are the types of injuries in modern dance, how to prevent these problems, and how to extend the career of dancers. Among them, the types of injuries in modern dance are the main research objects. From dance training, analyze and discuss the injuries, how they are, and why.

\section{Types of Dance Injuries (Take Modern Dance as an Example)}

Sports injuries may be caused by various external factors that cause injuries to the human body, causing functional damage to the body parts, and may cause people to have local or systemic reactions during exercise or at other times (Shuer \& Dietrich, 1997). There are many reasons for sports injuries, such as the intensity of training, the difficulty of exercise techniques, the props used during exercise, and the sports environment have a direct or indirect relationship (Angioi et al., 2009). Musculoskeletal injuries in dance can be divided into chronic injuries, and acute injuries, chronic injuries of sports are most likely due to cumulative injuries caused by the human body in long-term, repetitive, and continuous movements, which are mainly manifested in tendinitis, stress fractures, neuromas, and bursitis (Zwerver, 2015). An acute injury can be caused by one or a momentary (sudden) violence, which is mainly manifested in fractures, soft tissue injuries, ligament injuries, and tendon ruptures (Goldman, Pavlov, \& Rubenstein, 1988).

In modern dance, the most common injuries are the ankle and knee (van Winden et al., 2019). However, studies have shown that the shin is also a frequently injured site in modern dance training (Baker et al., 2010). Although the injury site is roughly the same in different dance types, the causes and consequences are different. Take Martha Graham's current system as an example. Martha Graham's technology will start from ground training. The cooperative relationship between the knee and the center of the body will support most of the body's weight so that the weight of the human body carried by the knee will be light, so increase the ability of the knee to move freely (Bannerman, 1999). Of course, the complete technical training will be performed in different ways, but 
all ground training is prepared for subsequent high-altitude jumping and other training (Copeland, 2004). It can be seen that in the ground training that will pave the way for future modern dance training, due to the changeable and diverse movement connections, including flexion and extension, rolling and other movements on the ground, knees, and shin will frequently come into contact with the ground. When the dancer does not master the technical movements, knee and shin injuries are prone to occur. In the jumping practice of modern dance, if the rotation speed is too fast, the higher the speed at which the ankle is in contact with the ground, the higher the reaction force on the ankle, and the more likely it is to be injured (Christina et al., 2001). Moreover, if the dancer does not tighten the body or force incorrectly when jumping, it will be more likely to cause sports injuries (Rickman, 2012). For example, when we are practicing modern dance, we must accurately find the point of exertion and relaxation of remaining body parts, but this does not mean that the body is lax. If the dancer does not understand the dance movements properly, it will cause the wrong movement and make the muscles unable to support the development of movements that cause sports injuries. For example, when practicing the transition from standing to the ground, the process of landing from the ankles to the shin, then the knees to the thighs, without basic training, dancers can easily sprain their ankles and bump their shin and knees. Because there is a power chain between the foot, ankle, knee and pelvis, for example, the transitional rotation of the foot will affect the pelvis (Khamis \& Yizhar, 2007). When the support point of the human body does not conform to scientific mechanical principles, it is more likely to cause sports injury.

The movements of modern dance are diverse and varied and even have a lot of repetitive movements (Gardner, 2011). Mastering movements, especially skill projects, is beneficial for improving dancers' self-protection ability and promoting their comprehensiveness. However, technical skills have a durable, comprehensive nature, and the amount of exercise and exercise intensity is considerable, especially when industrial action such as rolling and jumping causes injuries (Lushington, 2017). For example, some rolling techniques require the knee to land on the ground multiple times and cause friction with the ground. Repeating these actions many times will inevitably lead to an increase in damage factors. On the other hand, in most modern dances, the connection of movements is emphasized (Bannerman, 1999). In other words, the fluidity of the dance is emphasized, the connection between various dance movements is strengthened, and the expressive power of modern dance is enhanced. However, this requires dancers to be freely retractable, have high-intensity bursts, and be able to quickly switch dance moves in a short period. Therefore, this dancer is very demanding. If the dancer lacks strength, coordination, or in the rapid change of movement Loss of balance, which can easily cause ankle sprains, is because muscle strength is not sufficient to support rapid transitions between movements (Wiesler et al., 1996).

Data show that the highest injury rate in modern dance is the ankle $(30 \%)$ (van Winden et al., 2019), which is mainly manifested as acute sprains, strains 
around the ligaments around the ankle, etc. In the ankle joint, the ligaments of the lateral malleolus are weaker than those of the medial malleolus. Therefore, when a dancer performs jumps or moves quickly if the position of the ankle joints is not coordinated in time, it is easy to cause lateral ligament injuries. Therefore, when dancing, there is insufficient strength or excessive strength. It may cause a certain degree of sprain. Secondly, the shin injury rate is also prominent in modern dances, and it is a common specific injury in modern dances (Baker et al., 2010), which is mainly manifested as shin pain. Some external factors cause shin pain, such as the floor of the training venue. In modern dance, most dancers only dance in socks or barefoot (Wanke et al., 2014). Nevertheless, it also includes repeated jumps in dance training.

On the other hand, insufficient preparation activities are one of the main causes of sports injuries to dancers (Malliou et al., 2007). During the training process, dancers or teachers cannot realize the importance of preparation activities I think that my body is still very young, ignoring the necessity of warming up, and most people think that warming up is not necessary. Warming up is just a waste of time (Woods et al., 2007), which causes dancers to cause muscle strain, joint damage and other symptoms. Especially in modern dance, dancers are required to explore the relationship with space (Shick et al., 1983). It is not a single developmental movement, so it can be concluded that warm-up is an essential part of modern dance.

Secondly, in the teaching of dance practice, teachers' safety awareness is particularly important (Echegoyen et al., 2010). If the teacher's awareness of students' protection is poor, or they have a more one-sided understanding of dance injuries, or even they do not understand how to teach students to prevent sports injuries, this will result in teachers failing to make correct judgments and effective protection against dancers' mistakes in actual dance training. What is more, dancers can also cause injuries if they laugh and play during the training process, because dance partners are also one of the main causes of trauma (Wanke et al., 2014). In modern dance, in many cases, multiple people need to cooperate to complete the action, so this requires trust between the dancers and the establishment of a harmonious partnership, such as the improvisation training of two people in modern dance relay exercises, this requires the cooperation of two people, that is, from one person to another, the other person catches the dance partner and gives him a strength to develop the next relay, through these few back and forth relays to reflect the fluidity of modern dance (Copeland, 2004). However, such a multi-person dance movement requires teachers and dancers to have a full sense of safety, otherwise accidents such as falls and bumps may occur.

In addition, the long training time of the dancers can also cause sports injuries (Campoy et al., 2011). On the one hand, the teachers did not complete the teaching goals or expectations according to the dancers own conditions. On the other hand, the dancers themselves strictly required themselves and enthusiasm for dancing (Rip et al., 2006), therefore, when the local body burden is excessive, some damage will occur, and if it is accumulated for a long time, it will cause 
strain. Although modern dance is full of changes and uniqueness, it takes a lot of basic dance training and even other aerobic exercises and strength exercises to learn modern dance (Koutedakis et al., 2007). Therefore, under the difficult dance, modern dancers pay more time and energy to shape themselves, which means that the possibility of dancers being injured may be increased.

There are many other causes of dance damage. For example, the state of the dancer during training. Excessive tension and excessive excitement can easily cause muscle damage, because the dancer's physical function will show two states in fatigue and excitement (Swami \& Harris, 2012), this will cause the dancers to be unable to ensure the coordination or accuracy of the movements in normal training.

\section{Ways to Prevent Dance Injuries}

Athletes' sports injuries will affect many aspects. The first is that they cannot participate in training normally, and even cannot participate in competitions. This will cause huge psychological pressure, such as restlessness and loss of confidence, which may cause future careers for athletes obstruction (Pinkerton et al., 1989). Similarly, sports injuries are similar to a certain extent (Washington, 1978), so dancers may be accompanied by psychological injuries in addition to physical injuries.

On the other hand, the psychological injury will depend on the severity of the injury. The technical system of modern dance will require more physical fitness of dancers (Koutedakis et al., 2007), so if physical disabilities are caused during training, this may The dancer's life has a significant impact, and may even cause regrets for life. At the same time, if this happens, it will also have a harmful impact on dance teaching, especially in the practice of dance teaching. It can be seen that the purpose of proposing professional preventive measures and adding impromptu treatment information when dancers are injured to dance teaching is to reduce the frequency of dance injuries among students (Askling et al., 2002) and to ensure the scientific and safety of dance education.

In dance education, teachers need to accurately organize and arrange teaching plans and treat different classes of dance courses separately. For example, it is best to have a male teacher teaching or teaching assistant in the technical skills class of dance, because males will have some physical focus Strength training (Koutedakis \& Jamurtas, 2004), so when students need protective measures, male teachers are more suitable. For example, in modern double dance, there will be many lifted dance movements. When the dancer has a particular strength, the dance lift can be completed. So in order to ensure safety, male teachers have a vital role. However, the accompanying problem is that there are times when teachers are not responding in time, so it is especially crucial to strengthen students' own safety awareness and self-protection ability. On the other hand, the reasonable arrangement of dance teaching content (the establishment of dance injury prevention courses) and progress can also prevent dance injury (Fuhrmann et al., 2010). First of all, the teacher needs to understand the physical fit- 
ness level of each student, respect the difference of each person's situation in the classroom, when the students show load performance, they need to increase their vigilance, and let the students add energy to take a rest. Secondly, the setting of semester courses should be as reasonable as possible in the whole teaching (DiPasquale et al., 2015). For example, it is necessary to consider arranging several dance classes a week, how to do not conflict with other courses and can scientifically reserve dancers Rest time, but also need to consider the connection between the course content, make long-term arrangements for students to learn dance. Besides, flexible use of teaching methods can reduce the occurrence of dance injuries, such as multimedia teaching. Because the video can be repeatedly observed, analyzed, evaluated, and practiced, the technical quality of students is improved (Dania et al., 2011). Therefore, in this iterative process, it can also help teachers clearly understand the circumstances under which teachers need to protect students, thereby increasing reflection on dance education (Leijen et al., 2009).

Warm-up is essential for dance teaching, because warm-up can increase the excitability of the nervous system, strengthen the elasticity of muscle ligaments, prevent dancers from sports injuries during exercises. There is a statistically significant relationship between the incidence of injury and warming up and calming down (Malliou et al., 2007) because muscles and ligaments perform large-scale movements without proper warm-up and stretching. Secondly, if the teacher does not control the time after the student warms up in teaching, it will also cause sports injuries, because the student's body temperature will decrease with time. When the student officially enters the dance practice, the viscosity of the muscles and ligaments strengthens (Zatsiorsky, 1997), the effect of warming up no longer exists. Also, according to today's teaching content and characteristics, teachers can perform corresponding warm-up training on dance damage that may occur in this class. For example, in the classroom training of modern dance, in addition to the general warm-up (head, shoulder, soft stretch, small jump), the warm-up of the knee and ankle joints is also crucial, because this is a standard injured part in modern dance. Therefore, teachers need to consider the length of warm-up, the timing after warm-up, and the time of cooling and stretching to achieve the ideal effect.

In modern dance, taking the "Martha Graham" system as an example, contraction is the central point of the Martha Graham system, which is mainly reflected in the control of the body (Bannerman, 1999). Therefore, practicing core strength also plays a crucial role in preventing dance injuries. Because the core strength plays a role in the connection between the upper body and the lower body, the stability of the dancers can be effectively improved by training the core area strength (Rickman, 2012). For example, the practice of adding "center of gravity" in modern dance teaching, that is, the conversion of two legs during the process of travel, constantly changing the main leg and the power leg, or adding some rotation jumps, which not only requires the body's control ability, but also the dancer's responsiveness and flexibility are required. However, the basic idea 
when doing this exercise is to use the power of the abdomen to convert. All the turning and rotation are done by the abdomen consciously pushing the body, and the ability of the abdomen to contract in time also determines the speed of the next movement and whether can control his body to complete the movement. Therefore, it can be concluded that core training can strengthen the dancer's ability to control the body when the support point is unstable or under dynamic conditions so that it can better control the body and reduce the occurrence of injuries. At the same time, while training the core strength, a lot of lower body movements will be derived, such as walking, running, jumping, squatting, and turning, which are all done by the strength of the legs. Therefore, while training the core strength, the legs are also indirectly trained. Through this series of scientific training, muscle endurance will be significantly improved (Russell, 2013), thereby reducing the occurrence of dance injuries.

Besides, the facilities of the dance room also affect the chance of dancers being injured (Wanke, 2012). For example, whether the height of the room meets the standards of the dance room (to avoid the dancers hitting the lamps when doing the jumping exercise), is the ground rubber reliable, that is, most modern dancers are barefoot or only wear socks when dancing if there is a gap in the ground rubber, the dancer's feet (nails) will have a considerable safety risk; If the floor is too rough or too smooth, it may also cause abrasions on the dancer's feet, or the whole person fall. On the other hand, dancers should know how to strengthen their self-protection awareness, do their homework in advance when practicing dangerous moves, use the mat, knee pads, or seek the help of experienced people. Secondly, due to the influence of the dance classroom environment, dancers also need to learn to protect their bodies at different temperatures (Liederbach \& Richardson, 2007) and pay more attention to keeping warm in winter. Meanwhile, teachers also need to have a high sense of responsibility, master the methods of protection and help, teach students how to protect and help each other, and pay attention to the parts of protection, the timing of protection, and the amount of force when doing actions.

\section{Lifespan Development for the Dancer}

According to the survey (Weiss et al., 2008), professional modern dancers first started dancing classes at the age of 15.6 years for men and 6.5 years for women, and because most professional modern dancers started training from ballet in their youth, So it can be concluded that most modern dancers start with another kind of training method and then turn to modern dance training.

As the dancer's age, musculoskeletal development will become more and more mature (Anderson, 1996). At this time, the dancers may not have the same softness as teenagers. According to the survey (Solomon \& Micheli, 1986), at this time, technical skills are the main factor causing harm to modern dancers. Therefore, the strength of the feet and joint movement is particularly essential (Lushington, 2017), such as flying and jumping. Therefore, how to practice technical skills scientifically becomes the key to reduce sports injuries. What technical 
skills to practice are by the development of human bones at this time, and are good at using dance supplies to reduce the impact or friction of the ground on the feet. Secondly, since men and women have different bone development ages (Anderson, 1996) and different muscle qualities (Lacour, 1996), they can be studied in groups in modern dance technique classes, that is, the skills of men and women are different.

On the other hand, according to the survey (Weiss et al., 2008), professional dancers will frequently perform in large-scale dance groups, and professional modern dancers still need to participate in dance training to maintain technical level, and have $80 \%$ of modern dancers will participate in modern dance techniques. In addition to the usual dance training, many modern dancers also participate in other forms of exercise. For example, male dancers mainly choose to lift weights; female dancers mainly choose Pilates. Therefore, it can be inferred that in addition to technical skills being the leading cause of sports injuries, vigorous exercise for a long time can also cause musculoskeletal injuries. Therefore, school teachers, dance companies, and dancers themselves need to arrange training time reasonably and set up a clear training plan according to the dancers' own conditions. At the same time, professional dancers will cause negative psychological emotions due to employment pressure (Maddren, 2019). Therefore, in professional dance companies, in order to better the development of dancers, it is necessary to have a professional psychological counselor and dietitian.

According to another survey (Rönkkö et al., 2007), the average age of modern dancers is 50 years (42 to 60 years). Older modern dancers have increased leg problems caused by knee pain. This is because with age, people will have osteoporosis (Leppanen et al., 2008), and when the musculoskeletal health of the dancers, the slight symptoms caused by pain do not attract enough attention, as the muscles and bones further aging, a series of symptoms such as lower extremity osteoarthritis. Secondly, the survey also shows that retired modern dancers will also experience back pain, which may also be because some retired dancers have become dance teachers. At the same time, the degradation of the joints of retired dancers is most common in the feet and ankles (Lushington, 2017). Therefore, it can be inferred from the foregoing that the injury situation of modern dancers' feet in old age or after retirement is also a problem. Therefore, in this age group, modern dancers need to pay more attention to their own protection, reduce vigorous exercise, pay attention to warmth, and participate in some recovery training. For example, the use of appropriate modern dance and dance for health care treatment (Levy, 1988).

\section{Conclusion}

In summary, increasing the research on dance injury in dance education can reduce the chance of dancers being injured. The common injuries of modern dancers are ankles, knees, and shin, which are mainly caused by insufficient preparation time, insufficient safety awareness of teachers, too long training time 
and other external environmental factors. Therefore, make scientific arrangements in the dance teaching curriculum and teaching plan, improve the protection awareness of teachers and dancers, focus on training core strength in modern dance, and improve the venue facilities can effectively reduce the chance of dancer damage. Also, the injuries faced by dancers at different ages are different. Dance educators need to make appropriate solutions according to different situations in order to extend the lifespan of dancers.

\section{Conflicts of Interest}

The author declares no conflicts of interest regarding the publication of this paper.

\section{References}

Anderson, J. J. B. (1996). Calcium, Phosphorus and Human Bone Development. The Journal of Nutrition, 126, 1153S-1158S. https://doi.org/10.1093/jn/126.suppl 4.1153S

Angioi, M. et al. (2009). Physical Fitness and Severity of Injuries in Contemporary Dance. Medical Problems of Performing Artists, 24, 26-29.

Askling, C., Lund, H., Saartok, T. et al. (2002). Self-Reported Hamstring Injuries in Student-Dancers. Scandinavian Journal of Medicine \& Science in Sports, 12, 230-235. https://doi.org/10.1034/j.1600-0838.2002.00237.x

Baker, J. et al. (2010). Self-Reported and Reported Injury Patterns in Contemporary Dance Students. Medical Problems of Performing Artists, 25, 10-15.

https://doi.org/10.21091/mppa.2010.1003

Bannerman, H. (1999). An Overview of the Development of Martha Graham's Movement System (1926-1991). Dance Research, 17, 9-46. https://doi.org/10.3366/drs.1999.17.2.9

Caine, D. J., \& Nassar, L. (2005). Gymnastics Injuries. In D. J. Caine, \& N. Maffulli (Eds.), Epidemiology of Pediatric Sports Injuries (Vol. 48, pp. 18-58). Basel: Karger Publishers. https://doi.org/10.1159/000084282

Campoy, F. A. S., de Oliveira Coelho, L. R., Bastos, F. N. et al. (2011). Investigation of Risk Factors and Characteristics of Dance Injuries. Clinical Journal of Sport Medicine, 21, 493-498. https://doi.org/10.1097/JSM.0b013e318230f858

Christina, K. A., White, S. C., \& Gilchrist, L. A. (2001). Effect of Localized Muscle Fatigue on Vertical Ground Reaction Forces and Ankle Joint Motion during Running. Human Movement Science, 20, 257-276. https://doi.org/10.1016/S0167-9457(01)00048-3

Copeland, R. (2004). Merce Cunningham: The Modernizing of Modern Dance. New York: Routledge. https://doi.org/10.4324/9780203641989

Dania, A., Hatziharistos, D., Koutsouba, M. et al. (2011). The Use of Technology in Movement and Dance Education: Recent Practices and Future Perspectives. Procedia-Social and Behavioral Sciences, 15, 3355-3361. https://doi.org/10.1016/j.sbspro.2011.04.299

DiPasquale, S., Becker, N., Green, S. et al. (2015). Self-Reported Injury and Management in a Liberal Arts College Dance Department. Medical Problems of Performing Artists, 30, 224-231. https://doi.org/10.21091/mppa.2015.4041

Echegoyen, S., Acuña, E., \& Rodríguez, C. (2010). Injuries in Students of Three Different Dance Techniques. Medical Problems of Performing Artists, 25, 72-74.

https://doi.org/10.21091/mppa.2010.2014 
Fuhrmann, T. L., Brayer, A., Andrus, N. et al. (2010). Injury Prevention for Modern Dancers: A Pilot Study of an Educational Intervention. Journal of Community Health, 35, 527-533. https://doi.org/10.1007/s10900-010-9223-Z

Gardner, S. M. (2011). From Training to Artisanal Practice: Rethinking Choreographic Relationships in Modern Dance. Theatre, Dance and Performance Training, 2, 151-165. https://doi.org/10.1080/19443927.2011.603593

Goldman, A. B., Pavlov, H., \& Rubenstein, D. (1988). The Segond Fracture of the Proximal Tibia: A Small Avulsion That Reflects Major Ligamentous Damage. American Journal of Roentgenology, 151, 1163-1167. https://doi.org/10.2214/ajr.151.6.1163

Khamis, S., \& Yizhar, Z. (2007). Effect of Feet Hyperpronation on Pelvic Alignment in a Standing Position. Gait \& Posture, 25, 127-134. https://doi.org/10.1016/j.gaitpost.2006.02.005

Koutedakis, Y., \& Jamurtas, A. (2004). The Dancer as a Performing Athlete. Sports Medicine, 34, 651-661. https://doi.org/10.2165/00007256-200434100-00003

Koutedakis, Y., Hukam, H., Metsios, G. et al. (2007). The Effects of Three Months of Aerobic and Strength Training on Selected Performance- and Fitness-Related Parameters in Modern Dance Students. The Journal of Strength \& Conditioning Research, 21, 808-812. https://doi.org/10.1519/00124278-200708000-00026

Lacour, R. (1996). Physiological Analysis of Qualities Required in Sprinting. New Studies in Athletics, 11, 59-62.

Leijen, Ä., Lam, I., Wildschut, L. et al. (2009). Streaming Video to Enhance Students' Reflection in Dance Education. Computers \& Education, 52, 169-176. https://doi.org/10.1016/j.compedu.2008.07.010

Leppanen, O. V., Sievanen, H., Jokihaara, J. et al. (2008). Pathogenesis of Age-Related Osteoporosis: Impaired Mechano-Responsiveness of Bone Is Not the Culprit. PLoS $O N E, 3$, e2540.

Levy, F. J. (1988). Dance/Movement Therapy. A Healing Art. Waldorf, MD: AAHPERD Publications.

Liederbach, M., \& Richardson, M. (2007). The Importance of Standardized Injury Reporting in Dance. Journal of Dance Medicine \& Science, 11, 45-48.

Lushington, N. (2017). The Value of Teaching Classical Modern Dance Technique in Higher Education. Dance Education in Practice, 3, 25-29.

https://doi.org/10.1080/23734833.2017.1272289

Maddren, K. (2019). Dancers' Experience of Osteopathy and Their Attitudes towards Dance Injuries. Thesis, Auckland: Unitec Institute of Technology.

Malliou, P., Rokka, S., Beneka, A. et al. (2007). Reducing Risk of Injury Due to Warm up and Cool Down in Dance Aerobic Instructors. Journal of Back and Musculoskeletal Rehabilitation, 20, 29-35. https://doi.org/10.3233/BMR-2007-20105

Pinkerton, R. S., Hinz, L. D., \& Barrow, J. C. (1989). The College Student-Athlete: Psychological Considerations and Interventions. Journal of American College Health, 37, 218-226. https://doi.org/10.1080/07448481.1989.9939063

Rickman, A. M. (2012). Core Stability: Implications for Dance Injuries. Medical Problems of Performing Artists, 27, 159-164. https://doi.org/10.21091/mppa.2012.3028

Rip, B., Fortin, S., \& Vallerand, R. J. (2006). The Relationship between Passion and Injury in Dance Students. Journal of Dance Medicine \& Science, 10, 14-20.

Rönkkö, R. et al. (2007). Musculoskeletal Pain, Disability and Quality of Life among Retired Dancers. Journal of Dance Medicine \& Science, 11, 105-109. 
Russell, J. A. (2013). Preventing Dance Injuries: Current Perspectives. Open Access Journal of Sports Medicine, 4, 199-210. https://doi.org/10.2147/OAJSM.S36529

Shick, J., Stoner, L. J., \& Jette, N. (1983). Relationship between Modern-Dance Experience and Balancing Performance. Research Quarterly for Exercise and Sport, 54, 79-82. https://doi.org/10.1080/02701367.1983.10605276

Shuer, M. L., \& Dietrich, M. S. (1997). Psychological Effects of Chronic Injury in Elite Athletes. Western Journal of Medicine, 166, 104-109.

Solomon, R. L., \& Micheli, L. J. (1986). Technique as a Consideration in Modern Dance Injuries. The Physician and Sports Medicine, 14, 83-90.

https://doi.org/10.1080/00913847.1986.11709150

Swami, V., \& Harris, A. S. (2012). Dancing toward Positive Body Image? Examining Body-Related Constructs with Ballet and Contemporary Dancers at Different Levels. American Journal of Dance Therapy, 34, 39-52. https://doi.org/10.1007/s10465-012-9129-7

Van Winden, D. P. A. M. et al. (2019). Detailed Injury Epidemiology in Contemporary Dance: A 1-Year Prospective Study of 134 Students. BMJ Open Sport \& Exercise Medicine, 5, e000453.

Wanke, E. M. (2012). Dance Floors as Injury Risk: Analysis and Evaluation of Acute Injuries Caused by Dance Floors in Professional Dance with Regard to Preventative Aspects. Medical Problems of Performing Artists, 27, 137-142. https://doi.org/10.21091/mppa.2012.3025

Wanke, E. M., Arendt, M., Mill, H. et al. (2014). Traumatic Injuries in Revue Dancers. Journal of Dance Medicine \& Science, 18, 22-28. https://doi.org/10.12678/1089-313X.18.1.22

Washington, E. L. (1978). Musculoskeletal Injuries in Theatrical Dancers: Site, Frequency, and Severity. The American Journal of Sports Medicine, 6, 75-98. https://doi.org/10.1177/036354657800600207

Weiss, D. S., Shah, S., \& Burchette, R. J. (2008). A Profile of the Demographics and Training Characteristics of Professional Modern Dancers. Journal of Dance Medicine \& Science, 12, 41-46.

Wiesler, E. R., Hunter, D. M., Martin, D. F. et al. (1996). Ankle Flexibility and Injury Patterns in Dancers. The American Journal of Sports Medicine, 24, 754-757. https://doi.org/10.1177/036354659602400609

Woods, K., Bishop, P., \& Jones, E. (2007). Warm-Up and Stretching in the Prevention of Muscular Injury. Sports Medicine, 37, 1089-1099. https://doi.org/10.2165/00007256-200737120-00006

Zatsiorsky, V. M. (1997). On Muscle and Joint Viscosity. Motor Control, 1, 299-309. https://doi.org/10.1123/mcj.1.4.299

Zwerver, J. H. (2015). Sports Injuries. In A. Glaudemans, R. Dierckx, J. Gielen, \& J. Zwerver (Eds.), Nuclear Medicine and Radiologic Imaging in Sports Injuries (pp. 49-67). Berlin, Heidelberg: Springer. https://doi.org/10.1007/978-3-662-46491-5 4 